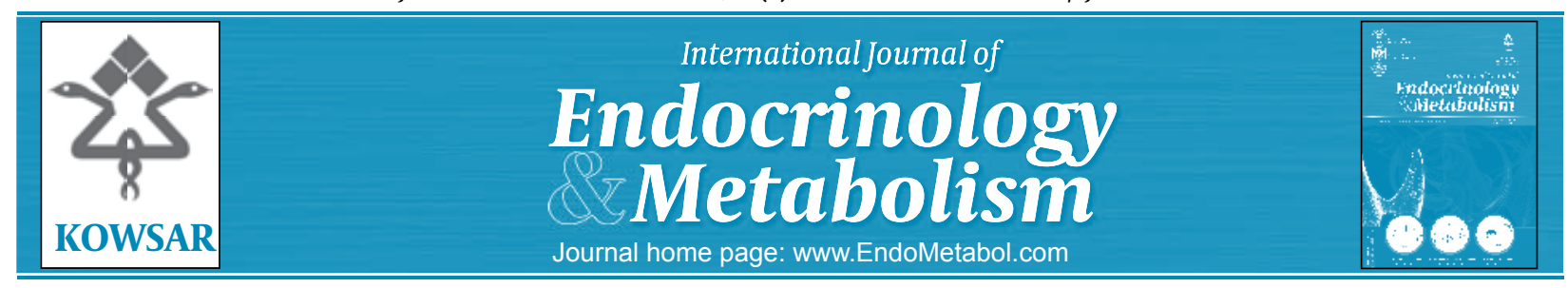

\title{
Diminished Response of Isolated Aorta Following Chronic Physical and Psychological Stresses and its Reversibility in Rats
}

\author{
Asghar Ghasemi ${ }^{1}$, Farzaneh Faraji ${ }^{1}$, Faraz Valaee ${ }^{1}$, Katayon Sedaghat ${ }^{1}$, Maedeh Arabian ${ }^{1}$, \\ Saleh Zahediasl ${ }^{1^{*}}$ \\ ${ }^{1}$ Endocrine Research Center, Research Institute for Endocrine Sciences Shahid Beheshti University of Medical Sciences, Tehran, IR Iran
}

\begin{tabular}{l}
\hline A R T I C L E I N F O \\
\hline Article type: \\
Original Article \\
\hline Article history: \\
Received: 05 Nov 2011 \\
Revised: 06 Dec 2011 \\
Accepted: 22 Dec 2011 \\
\hline
\end{tabular}

\section{Keywords:}

Restraint

Physical

Stress

Psychological

Aorta

Rat \begin{abstract}
A B S T R A C T
Background: The role of stress has been elucidated in cardiovascular disorders. The aim of this study was to determine and compare the effects of chronic physical and psychological stress on the contractility of isolated rat aorta and their reversibility. Materials and Methods: Wister rats were divided into 3 groups: control, physical stress, and psychological stress $(n=12)$. Animals were kept on 12-h/12-h light/dark cycles at $22 \pm$ $2^{\circ} \mathrm{C}$ and had free access to food and water. Physical and psychological stress was induced using a communication box for 3 weeks. Physical stress was applied with electrical current $(1 \mathrm{~mA}, 1 \mathrm{~Hz}, 10 \mathrm{sec} / \mathrm{min}) 1$ hour twice daily. To assess the aortic response, the animals were anesthetized, abdominal aortas were removed, and the contractility response to potassium chloride and phenylephrine was measured with an isometric transducer. To study the reversibility of the effects, separate groups of stressed animals and a control group ( $\mathrm{n}=12$ in each group) were kept for 1 month following the stress period, and the aortic responses were evaluated and compared.

Results: In the stressed group, the aortic responses to potassium chloride and phenylephrine were significantly lower compared with the controls, whereas the corticosterone concentration was higher. Following a 1-month recovery, both values returned to normal.

Conclusions: Chronic physical stress and psychological stress have similar effects on vascular responsiveness, which are reversible; these findings may be clinically important in the treatment of stress-related cardiovascular disorders.
\end{abstract}

Copyright $\odot 2012$ Kowsar M. P. Co. All rights reserved.

- Implication for health policy/practice/research/medical education:

Although the study has been performed in animal model, the findings will shed some more lights on the impacts of two types of stresses on cardiovascular system

Please cite this paper as:

Ghasemi A, Faraji F, Valaee F, Sedaghat K, Arabian M, Zahediasl S. Diminished Response of Isolated Aorta Following Chronic Physical and Psychological Stresses and its Reversibility in Rats. Int J Endocrinal Metab.2012; 10(1): 423-8. DOI: 10.5812/ijem.4062

\section{Background}

The concept of stress implies alterations in the homeostasis or balance of physiological systems, which can lead to morbidity. Nowadays, the term "homeostasis" has been replaced by the concept of allostasis, which is more

* Corresponding author: Saleh Zahediasl, Endocrine Research Center, Research Institute for Endocrine Sciences Shahid Beheshti University of Medical Sciences, Tehran, IR Iran. Tel: +98-2122432513, Fax: +98-2122402463,

E-mail: zahedi@endocrine.ac.ir

DOI:10.5812/ijem.4062

Copyright $\odot 2012$ Kowsar M.P. Co. All rights reserved. flexible (1) and is the process by which complex physiological systems adapt to physical, psychosocial, and environmental stress (2). Stress can induce disparities between afferent information received and a set point for a response; ultimately, it activates multiple mechanisms to reduce these disparities (3). Activation of the hypothalamic-pituitary-adrenal (HPA) axis and sympathetic adrenomedullary (SA) systems is the principal response to stress (4). The effects of chronic physical and psychological stress have been investigated in clinical settings and experimental models. It has been shown that physical 
stress can significantly affect hemodynamics, artery plasticity, and pulse pressure (5). Activation of the autonomic nervous system following stress increases artery rigidity, which is associated with increased catecholamine and angiotensin-II concentrations in circulation (5). Gu et al. have shown that mild chronic physical stress can cause atherosclerosis (6). Accumulating evidence indicates that psychological stress can also induce acute cardiovascular disorders, including myocardial ischemia and arrhythmia (7). In subjects with posttraumatic stress disorder, the risks of hypertension, hyperdyslipidemia, obesity, and coronary heart disease increase (8). It has been shown that after cold restraint stress, the contractility response of rat aorta to norepinephrine, angiotensin II, and vasopressin is significantly reduced (9). Chronic social stress can significantly reduce NO synthase activity in the aorta, increases blood pressure, and is accompanied by extensive subcellular injury to endothelial cells in the aorta (10). Both alpha- and beta-adrenoceptors are affected by emotional or physical stress (11).

Although the adverse effects of both physical and psychological stress have been studied, their reversibility is unknown. In this study, we examined the reversibility of the effects of both types of stress on the contractility of isolated aorta in rats.

\section{Materials and Methods}

Animals and agents: Adult male Wistar rats (200-250 g) were obtained from the Shahid Beheshti University of Medical Sciences animal facility. Animals were kept at 22 $\pm 2^{\circ} \mathrm{C}$ under 12-h light-dark cycles and had free access to tap water and standard rat chow (Pars Co. Tehran, Iran). All procedures were performed per the standards for animal care, established by the ethical committee of the Research Institute for Endocrine Sciences. Phenylephrine was purchased from Sigma (USA), and all other chemicals were obtained from Merck (Germany). To induce physical and psychological stress, a communication box was locally manufactured according to the protocol, consisting of 9 small compartments, divided by transparent Plexiglas walls. Five compartments were wired with electric foot shock generators; the physical stress group comprised animals that were placed in these spaces. Four other compartments were used to induce psychological stress (12).

\subsection{Experiments}

Stress protocol: Each phase of the study (stress effects and reversibility of the effects) was performed using 3 groups: control, physical stress, and psychological stress animals ( $\mathrm{n}=12$ each). Physical and psychological stress was induced for 3 weeks using the communication box. Physical stress was induced through electrical shocks to the foot $(1 \mathrm{~mA}, 1 \mathrm{~Hz}, 10 \mathrm{sec} / \mathrm{min}$ ) for 1 hour twice daily. Animals in the psychological stress group were subjected to stress, caused by observing physically stressed animals during the stress sessions (12). Animals in the con- trol group were kept in the communication box for the same period but did not receive a shock. To observe the reversibility of the effects, 2 separate groups of stressed animals and a control group were allowed a 1-month recovery period after the stress protocol.

\subsection{Contractility Assessment}

To assess the contractility of the isolated aorta, the animals were anesthetized with ketamin, the abdomen was opened, blood samples were collected from the abdominal aorta, and thoracic aortas were rapidly removed. The isolated aortas were cleansed of extraneous connective and fatty tissue in cold Krebs-Henseleit solution [ $\mathrm{NaCl}$ (118), $\mathrm{KCl}$ (4.7), $\mathrm{CaCl}_{2}$ (2.52), $\mathrm{MgSo}_{4}$ (1.64), $\mathrm{KH}_{2} \mathrm{Po}_{4}$ (1.18), $\mathrm{NaHCO}_{3}$ (7) and glucose (5.5), all in mmol/L, gassed with carbogen $\left(95 \% \mathrm{O}_{2}, 5 \% \mathrm{CO}_{2}\right), \mathrm{pH} 7.4,37^{\circ} \mathrm{C}$ ] and cut into rings 3-5 $\mathrm{mm}$ long. The endothelium was denuded by rubbing the aorta ring between the fingers and tissue, transferred to an organ bath, and attached to an isometric force transducer (UF1) and a Harvard oscillograph. The tissue was maintained under $2 \mathrm{~g}$ of tension (Park et al., 2009) and allowed to equilibrate for $60-90 \mathrm{~min}$, during which the bath solution was refreshed every $15 \mathrm{~min}$ (13). After equilibrium was reached, the absence of endothelium was assessed, based on of the relaxation that was evoked by the endothelium-dependent dilator acetylcholine (1 $\mu \mathrm{m})$ in aorta rings that were precontracted with phenylephrine $(1 \mu \mathrm{m})$ (13). The contractility was assessed in response to 5-60 mM potassium chloride and $10^{-10}-10^{-6} \mathrm{M}$ phenylephrine. At the end of each experiment, the tissue was demisted, and its length and weight were measured to calculate tension, normalized for cross-sectional area, using the following formula: cross sectional area $\left(\mathrm{mm}^{2}\right)$ = weight $(\mathrm{mg}) /[$ length $(\mathrm{mm}) \times$ density] $(14)$, where density of vascular smooth muscle $=1.05 \mathrm{mg} / \mathrm{mm}^{3}$.

Phenylephrine and $\mathrm{KCl}$ responses were expressed as $\mathrm{g} /$ $\mathrm{mm}^{2}$.

\subsection{Measurement of Corticosterone Levels and Adrenal Weight}

The adrenal gland was dissected, cleansed of extraneous connective and fatty tissue, and weighed on an electronic balance with $0.1 \mathrm{mg}$ of friction (Sartorius, Germany). Plasma corticosterone concentration was measured by radioimmunoassay (DRG Germany). The intraassay coefficient variation was $7.2 \%$.

\subsection{Statistical Analysis}

Data were expressed as mean \pm SE and analyzed by oneway or two-way ANOVA, followed by Tukey post hoc test as appropriate; $P$ value $<0.05$ was considered significant.

\section{Results}

\subsection{Isolated Aorta Contractility}

Aortic responses to $10^{-10}-10^{-6} \mathrm{mM}$ phenylephrine at the end of the stress period in the physically stressed group were $0.29 \pm$ 
$0.04,0.65 \pm 0.14,1.2 \pm 0.19,1.76 \pm 0.15$, and $1.91 \pm 0.17 \mathrm{~g} / \mathrm{mm}^{2}$ and $0.26 \pm 0.05,0.61 \pm 0.11,1.18 \pm 0.14,1.72 \pm 0.09$, and $1.83 \pm 0.13 \mathrm{~g} / \mathrm{mm}^{2}$ in the psychologically stressed group, which were significantly lower $(P<0.05)$ compared with the control group $(0.51 \pm 0.09$, $1.12 \pm 0.17,1.72 \pm 0.13,2.21 \pm 0.14$, and $\left.2.38 \pm 0.16 \mathrm{~g} / \mathrm{mm}^{2}\right)$. There was no significant difference between the physically and psychologically stressed groups. Following recovery from both types of stress, the aortic responses did not differ significantly versus the control group (Figure 1). Isolated aortic contractility in response to 5,10,20, 40, and $60 \mathrm{mM}$ potassium chloride after the stress period in the physically stressed group $(0.23 \pm 0.03,0.46$ $\pm 0.07,0.8 \pm 0.04,1.16 \pm 0.11$, and $\left.1.06 \pm 0.08 \mathrm{~g} / \mathrm{mm}^{2}\right)$ and psychologically stressed group $(0.23 \pm 0.03,0.47 \pm 0.05,0.81 \pm 0.05,1.04$ \pm 0.11 , and $\left.1.08 \pm 0.11 \mathrm{~g} / \mathrm{mm}^{2}\right)$ fell significantly compared with the control group $(0.37 \pm 0.06,1.11 \pm 0.1,1.16 \pm 0.90,1.52 \pm 0.11$, and $\left.1.64 \pm 0.17 \mathrm{~g} / \mathrm{mm}^{2}\right)(P<0.05)$. There was no significant difference between the physically and psychologically stressed groups. After a 1-month recovery period, there was no significant difference in contractility between the control and physically and psychologically stressed groups (Figure 2).

Figure 1. Contractility Responses to Phenylephrine in all Groups at the End of Stress Period (A) and After one Month Recovery Period (B)
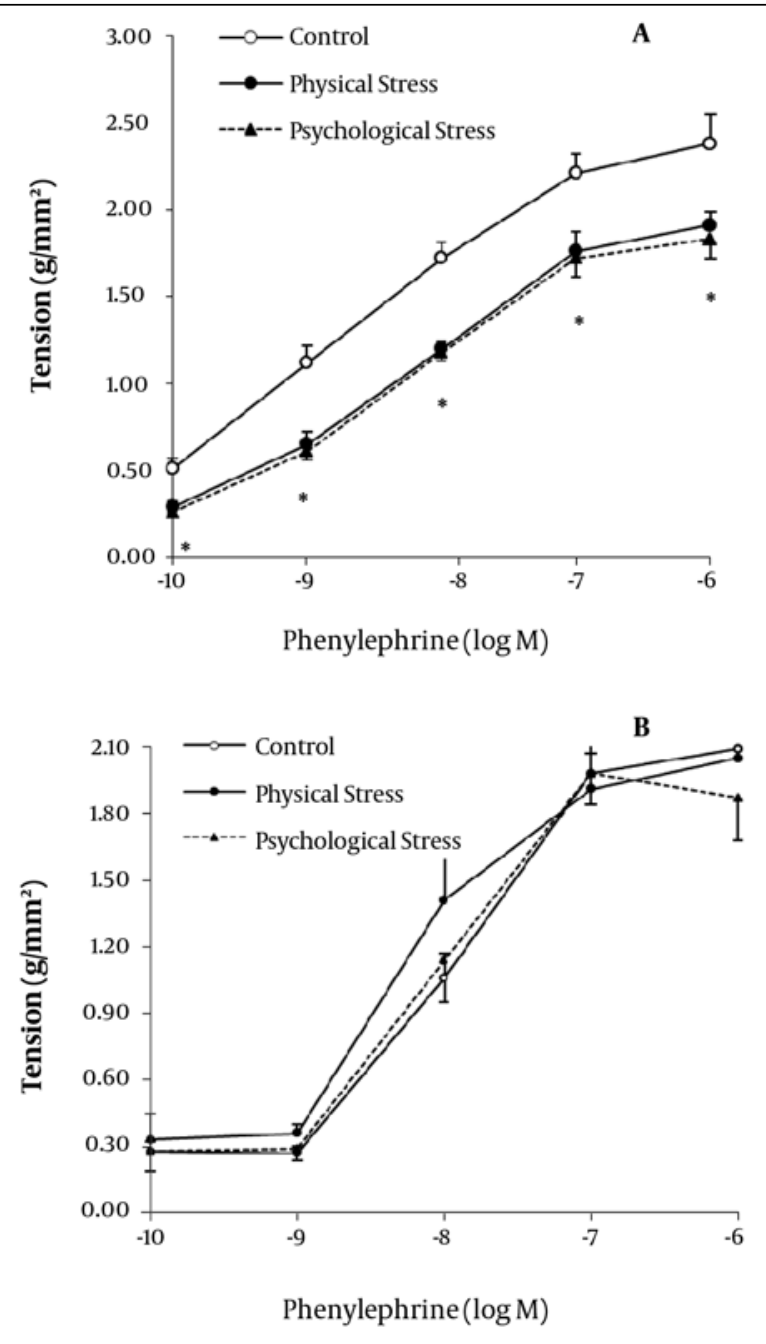

${ }^{*} P<0.05$
Figure 2. Contractility Responses to Potassium Chloride in the Control, and the Physically and Psychologically Stressed Groups at the end of Stress Period (A) and After One Month Recovery Period (B)
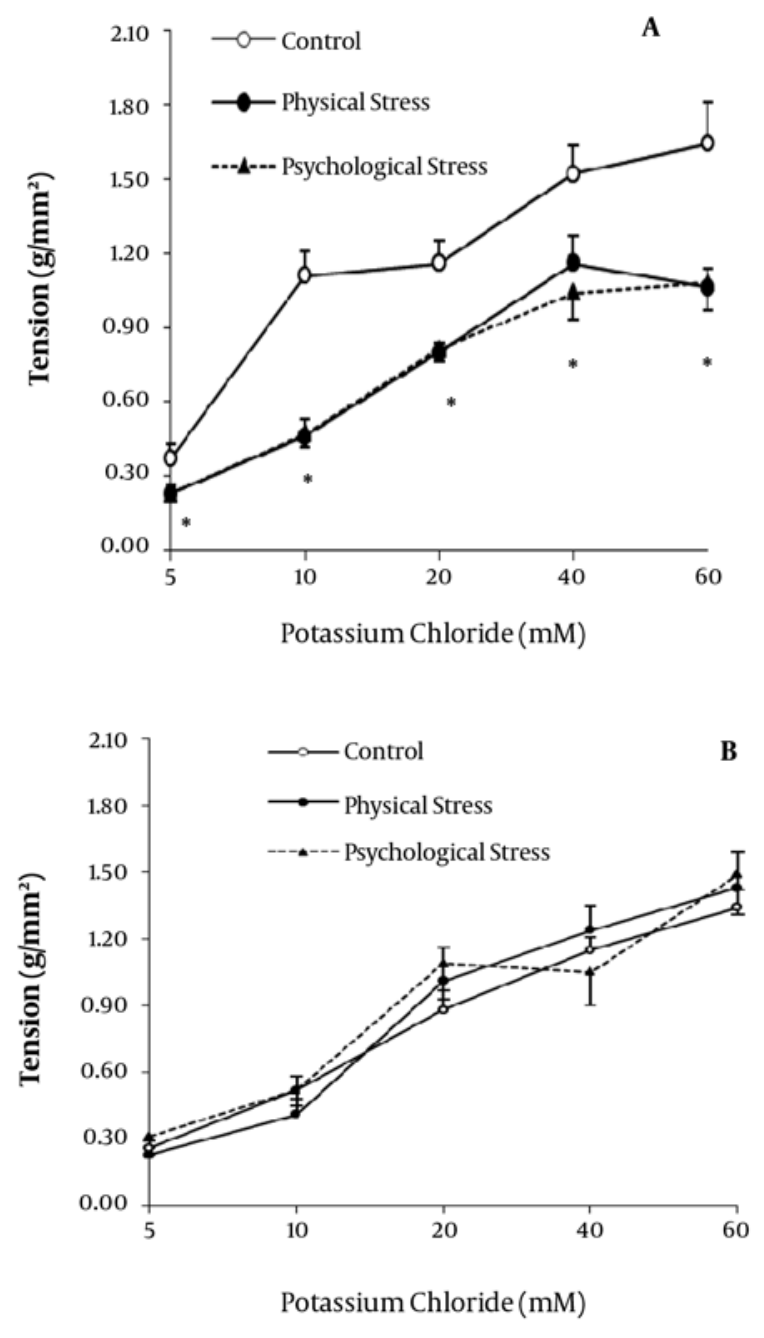

${ }^{*} P<0.05$

3.2. The Effect of Stress on Serum Corticosterone Concentration

Serum corticosterone levels at the start $(523 \pm 72 \mathrm{ng} / \mathrm{mL})$ and end of the stress period $(592 \pm 87 \mathrm{ng} / \mathrm{mL})$ in the control group did not differ significantly. In the physically stressed group, serum corticosterone levels rose significantly ( $P$ $<0.05)$ from $402 \pm 40$ to $721 \pm 94 \mathrm{ng} / \mathrm{mL}(P<0.05)$; in the psychologically stressed group, they reached $946 \pm 84$ from an initial value of $400 \pm 114 \mathrm{ng} / \mathrm{mL}(P<0.05)$. At the end of the stress period, there were no significant differences in corticosterone concentrations between the physically and psychologically stressed groups. After a 1-month recovery period, serum corticosterone levels did not differ significantly from basal values in any group (Figure 3).

\subsection{Effect of Stress on Adrenal Weight}

Adrenal weight following the 1-month stress period was significantly $(P<0.05)$ higher in the physically stressed group (10.3 $\pm 0.4 \mathrm{mg} / 100 \mathrm{~g}$ body weight) compared with 
Figure 3. Serum Corticosterone Levels in the Controls, and the Physically and Psychologically Stressed Groups at the end of the Stress Period (A) and After one Month Recovery Period (B)
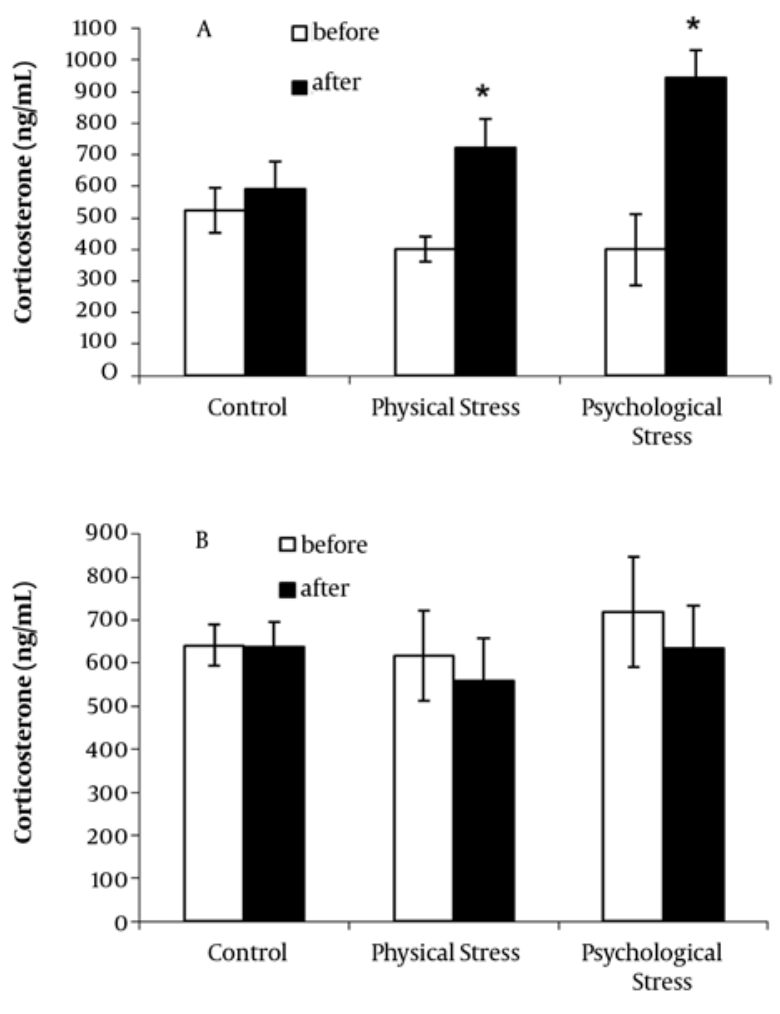

${ }^{*} P<0.05$

the control group $(8.1 \pm 0.6)$. The increase in weight of the adrenal gland in the psychologically stressed group ( 8.5 \pm 0.5 ) was not significant (Figure 4).

Figure 4. Adrenal Weight at the End of the Stress Period and the One Month Recovery Period in the Controls, and the Physically and Psychologically Stressed Groups

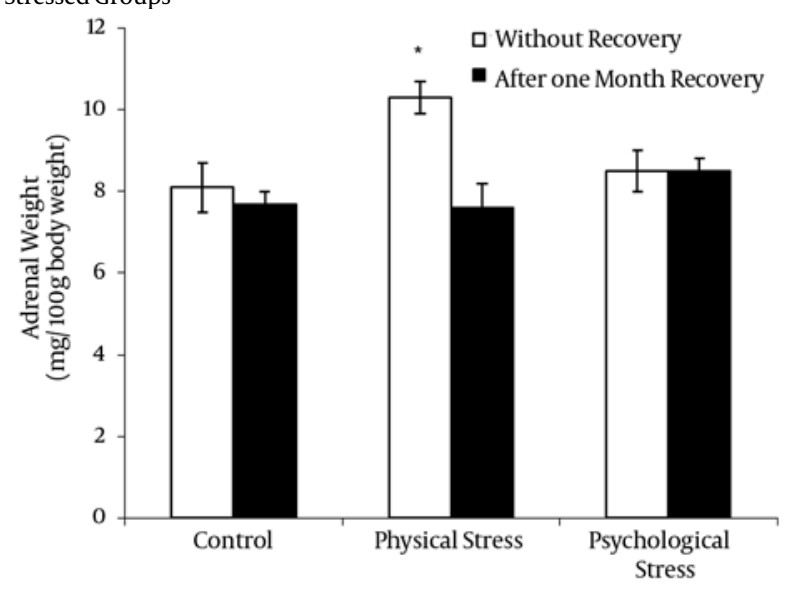

${ }^{*} P<0.05$

\section{Conclusions}

The results of this study show that both chronic psychological and physical stress can significantly reduce the contractility of aortas in response to potassium chloride and phenylephrine, underscoring the importance and similarity of the impact of both types of stress on the cardiovascular system.

The effects of stress on cardiovascular responses, as studied by other investigators applying different tools, are similar to ours. One study showed that cold restraint stress in rats significantly reduces aortic contractility to norepinephrine, angiotensin II, and vasopressin, which may result from decreased receptor density and affinity or reduced effector efficacy (9). It has also been reported that aortic contractility to the alpha-adrenoceptor agonist phenylephrine is reduced with restraint stress in rennin enhancer knockout mice (15). However, Andrews et al. showed that social stress induces hypertension in mammals, attributed to collagen deposition in the coronary and mesenteric arteries and to myocardial fibrosis (16). Although structural components of the aorta were not evaluated in this study, the reduced contractility of the vascular bed observed in this study is difficult to be explained by structural alterations, such as collagen deposition. It has been suggested that the vascular response to stress is associated with hyperstimulation of adrenergic receptors. Alpha 1 adrenergic receptor stimulation with phenylephrine results in hypertension, reflexive bradycardia, and induction of HSP70 mRNA in aorta smooth muscle (17). It has been hypothesized that this reduction in aortic contractility following stress is due to downregulation of adrenergic receptors, subsequent to sympathetic hyperactivity (9). Nevertheless, the results of this study indicate that aortic contractility in response to potassium chloride after a stress period is significantly lower. Therefore, we presume that the diminished contractility of isolated aortas from stressed rats results from either a reduction in muscle mass or an alteration in the intracellular machinery of the contraction. Chronic stress induces hypertension (10), and it has been suggested that during long-term hypertension, remodeling of the vascular bed occurs through a complex mechanism involving growth apoptosis, inflammation, and matrix accumulation(18). It is obvious that under certain conditions, each of these mechanisms might have a different degree of contribution. Also, another study has indicated that the reduction in the contractile response in the aorta could be the result of mechanical alterations, resulting from changes in vascular structure, increased release of vasodilators, and alterations in the smooth muscle contraction signal transduction pathway (19). Since the current study was carried out using denuded aorta, it is possible to rule out the role of endothelial vasodilators; thus, the intracellular changes that are more likely to be due to changes in the muscle mass are signal transduction pathways. This study has also for the first time directly assessed the reversibility of stress effects on isolated aorta contractility, plasma corticosterone levels, and adrenal weight simultaneously. However, Wolinsky, in 1971, showed that hypertension induces changes in diameter; wall thickness; and the amounts of elastin, collagen, and noncollagenous protein in the walls of all 
hypertensive vessels, which reverted to normal levels 10 weeks after cessation of the hypertension (20). Interestingly, Radley et al. reported similar reversibility in apical dendrite retraction that was induced by a 6-week stress period after 3 weeks of recovery (21). The present study shows that corticosterone levels were significantly increased in response to both physical and psychological stress. Although a previous study reported that acute physical stress is more effective in inducing corticosterone secretion compared to psychological stress (7), the results of this study indicate that both types of stress, if chronic, act similarly. Nevertheless, adrenal weight in the physically stressed group was higher compared to the psychologically stressed group. Increased adrenal gland weight is a characteristic feature of the effects of stress in rats (22), but it seems that the effect of psychological stress on adrenal function differs somewhat from physical stress. Our current findings indicate that significant increases in adrenal weight occurred only in response to physical stress; adrenal weight increased in the psychologically stressed rats but was not significant, perhaps because it was associated with specific individual characteristics in response to psychological stress. A previous report has suggested that acute exposure to restraint stress induces expression of heat shock proteins (HSP70) in rat adrenal glands, but the expression in animals chronically exposed to restraint was unaltered (23). The results of this study show that both plasma corticosterone levels and adrenal weight returned to basal values after the 1-month recovery period, consistent with the return of the aortic response. One study has shown that stress increases NOS mRNA and protein levels in the adrenal gland and that increased NO synthesis can facilitate the recovery from elevated corticosterone secretion (24). In 1993, Blake demonstrated that in rat adrenal glands, restraint stress induced an elevation in HSP 72/73 protein expression within $1 \mathrm{~h}$; peaks levels were observed between 6 and $12 \mathrm{~h}$, and values returned to baseline levels $48 \mathrm{~h}$ after application of restraint stress (25). These findings, however, can not be compared with the results of our study, because the animals were exposed to much longer periods of chronic stress. From the results of this study, one can conclude that physical stress and psychological stress have similar impacts on the cardiovascular system. It also appears that at least some of the effects of these stresses are reversible, which may have clinical significance in the treatment of stress-related cardiovascular disorders.

\section{Acknowledgements}

This study was supported by a grant (No: 87) of Endocrine Research Center, Research Institute for Endocrine Sciences Shahid Beheshti University of Medical Sciences. The authors are thankful to Mrs. Vajihe Khorasani and Mr. Mohammad Shabani for their technical help. Linguistic editing of the manuscript by Ms N. Shiva is highly appreciated.

\section{Financial Disclosure}

None declared.

\section{Funding/Support}

None declared.

\section{References}

1. Le Moal M. Historical approach and evolution of the stress concept: a personal account. Psychoneuroendocrinology. 2007;32 (Suppl 1):S3-9.

2. Logan JG, Barksdale DJ. Allostasis and allostatic load: expanding the discourse on stress and cardiovascular disease. J Clin Nurs. 2008;17(7B):201-8.

3. Goldstein DS. Computer models of stress, allostasis, and acute and chronic diseases. Ann NYAcad Sci. 2008;1148:223-31.

4. Navarro-Oliveira CM, Vassilieff VS, Cordellini S. The sympathetic adrenomedullary system, but not the hypothalamic-pituitaryadrenal axis, participates in aorta adaptive response to stress: nitric oxide involvement. Auton Neurosci. 2000;83(3):140-7.

5. Plante GE. Vascular response to stress in health and disease. Metabolism. 2002;51 (Suppl 1):25-30.

6. Gu H, Tang C, Peng K, Sun H, Yang Y. Effects of chronic mild stress on the development of atherosclerosis and expression of tolllike receptor 4 signaling pathway in adolescent apolipoprotein E knockout mice. J Biomed Biotechnol. 2009;2009:613879.

7. Kario K, McEwen BS, Pickering TG. Disasters and the heart: a review of the effects of earthquake-induced stress on cardiovascular disease. Hypertens Res. 2003;26(5):355-67.

8. Coughlin SS. Post-traumatic Stress Disorder and Cardiovascular Disease. Open Cardiovasc Med J. 2011;5:164-70.

9. Tuncel N, Erkasap N, Sahinturk V. The effect of stress and in vivo vasoactive intestinal peptide (VIP) treatment on the response of isolated rat aorta to norepinephrine, angiotensin II and vasopressin, and adventitial mast cells. Stress. 2000;3(4):299-308.

10. Okruhlicova L, Dlugosova K, Mitasikova M, Bernatova I. Ultrastructural characteristics of aortic endothelial cells in borderline hypertensive rats exposed to chronic social stress. Physiol Res. 2008;57 (Suppl 2):S31-7.

11. Ueyama T. Emotional stress-induced Tako-tsubo cardiomyopathy: animal model and molecular mechanism. Ann N Y Acad Sci. 2004;1018:437-44.

12. Ishikawa M, Ohdo S, Watanabe H, Hara C, Ogawa N. Alteration in circadian rhythm of plasma corticosterone in rats following sociopsychological stress induced by communication box. Physiol Behav. 1995;57(1):41-7.

13. Khaksari M, Shafiee M, Ghasemi A, Asl SZ. Effect of orally administered propylthiouracil in pregnant and lactating rats on isolated aorta contractility of their adult male offspring. Med Sci Monit. 2009;15(4):BR123-7.

14. Arun KH, Kaul CL, Ramarao P. High glucose concentration augments angiotensin II mediated contraction via AT1 receptors in rat thoracic aorta. Pharmacol Res. 2004;50(6):561-8.

15. Jackson K, Head GA, Morris BJ, Chin-Dusting J, Jones E, La Greca L, et al. Reduced cardiovascular reactivity to stress but not feeding in renin enhancer knockout mice. Am J Hypertens. 2007;20(8):893-9.

16. Andrews E, Jenkins C, Seachrist D, Dunphy G, Ely D. Social stress increases blood pressure and cardiovascular pathology in a normotensive rat model. Clin Exp Hypertens. 2003;25(2):85-101.

17. Udelsman R, Li DG, Stagg CA, Gordon CB, Kvetnansky R. Adrenergic regulation of adrenal and aortic heat shock protein. Surgery. 1994;116(2):177-82.

18. Intengan HD, Schiffrin EL. Vascular remodeling in hypertension: roles of apoptosis, inflammation, and fibrosis. Hypertension. 2001;38(3 Pt 2):581-7.

19. Delp MD, Brown M, Laughlin MH, Hasser EM. Rat aortic vasoreactivity is altered by old age and hindlimb unloading. J Appl Physiol.1995;78(6):2079-86.

20. Wolinsky H. Effects of hypertension and its reversal on the thoracic aorta of male and female rats. Morphological and chemi- 
cal studies. Circ Res. 1971;28(6):622-37.

21. Radley JJ, Rocher AB, Janssen WG, Hof PR, McEwen BS, Morrison $\mathrm{JH}$. Reversibility of apical dendritic retraction in the rat medial prefrontal cortex following repeated stress. Exp Neurol. 2005;196(1):199-203.

22. Marti O, Armario A. Anterior pituitary response to stress: timerelated changes and adaptation. Int J Dev Neurosci. 1998;16(34):241-60.

23. Blake MI, Klevay LM, Halas ES, Bode AM. Blood pressure and heat shock protein expression in response to acute and chronic stress. Hypertension. 1995;25(4 Pt 1):539-44.
24. Tsuchiya T, Kishimoto J, Koyama J, Ozawa T. Modulatory effect of-NAME, a specific nitric oxide synthase (NOS) inhibitor, on stress-induced changes in plasma adrenocorticotropic hormone (ACTH) and corticosterone levels in rats: physiological significance of stress-induced NOS activation in hypothalamicpituitary-adrenal axis. Brain res. 1997;776(1-2):68-74.

25. Blake MJ, Buckley DJ, Buckley AR. Dopaminergic regulation of heat shock protein-70 expression in adrenal gland and aorta. Endocrinology. 1993;132(3):1063-70. 